
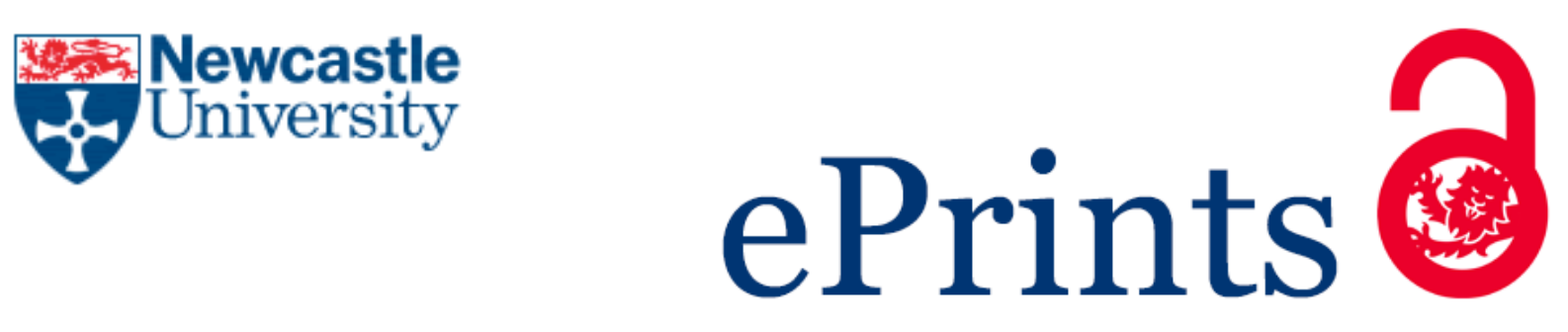

Lang P, Michel M, Wade NS, Grunbaum R, Larsson T. Dynamic energy storage - Field operation experience. In: 2013 IEEE Power and Energy Society General Meeting (PES). 2013, Vancouver, BC: IEEE.

\title{
Copyright:
}

C 2013 IEEE. Personal use of this material is permitted. Permission from IEEE must be obtained for all other uses, in any current or future media, including reprinting/republishing this material for advertising or promotional purposes, creating new collective works, for resale or redistribution to servers or lists, or reuse of any copyrighted component of this work in other works.

DOI link to article:

http://dx.doi.org/10.1109/PESMG.2013.6672820

Date deposited:

$03 / 03 / 2016$ 


\section{Dynamic Energy Storage - Field Operation Experience}

\author{
Peter Lang, Matthieu Michel \\ Future Networks Team \\ UK Power Networks \\ London, United Kingdom \\ peter.lang@ukpowernetworks.co.uk \\ matthieu.michel@ukpowernetworks.co.uk
}

\author{
Neal Wade \\ School of Engineering and Computing \\ Sciences \\ Durham University \\ Durham, United Kingdom \\ n.s.wade@durham.ac.uk
}

\author{
Rolf Grünbaum SM IEEE, \\ Tomas Larsson, SM IEEE \\ FACTS division \\ ABB \\ Västerås, Sweden \\ rolf.grunbaum@se.abb.com \\ tomas.x.larsson@se.abb.com
}

\begin{abstract}
For intermittent power sources like wind and solar, the challenge is to connect and integrate this type of generation while still meeting the required grid stability and reliability, particularly at a low reserve capacity level. This requires viable solutions of electrical energy storage both for distributed and bulk power applications. UK Power Networks has installed a dynamic energy storage system at a site in Norfolk in England in collaboration with ABB, and Durham University. The system is located in an $11 \mathrm{kV}$ network with some penetration of wind power. The paper highlights the grid characteristics, offers salient design features of the energy storage and gives some results from commissioning and the first power exchanges carried out. It also discusses uses of the installation in the $11 \mathrm{kV}$ grid with the aim of harnessing wind power more efficiently than was possible before.
\end{abstract}

Index Terms--Batteries, Energy storage system, Reactive power control, STATCOM, Voltage source converter

\section{INTRODUCTION}

The integration of dynamic energy storage into transmission and distribution systems has the potential to provide significant benefits to the supply chain. Until now, grids have been characterized by centralized power generation and one-directional power flow. Tomorrow's grids will to a higher degree be characterized by centralized and distributed generation, intermittent renewable power generation, and multi-directional power flow where consumers become also producers. The ever increasing demand for power, and the need of reducing $\mathrm{CO} 2$ emissions at the same time, requires the integration of more renewable power and distributed energy supply into the system. A future electric system that can handle those challenges in a sustainable, reliable and economic way is needed.

For intermittent power sources like wind and solar, the challenge is to connect and integrate them without compromising the required grid stability and reliability, particularly at a low reserve capacity level. This requires viable solutions of electrical energy storage both for distributed and bulk power applications. Dynamic energy storage will play a vital role in this field. UK Power Networks has installed a DynaPeaQ ${ }^{\circledR}$ dynamic energy storage system at
Hemsby in Norfolk in England in collaboration with ABB, and Durham University [1], [2], [3], see Fig. 1. The system is based on ABB's SVC Light ${ }^{\circledR}$, combined with a Lithium-ion, Li-ion, battery based energy storage located in an $11 \mathrm{kV}$ grid with some penetration of wind power.

\section{TEST NETWORK}

A site was selected such that the maximum range of benefits with the Energy Storage System, ESS, could be considered from a single installation. A rural $11 \mathrm{kV}$ distribution network in north Norfolk with a $2.25 \mathrm{MW}$ wind farm connection was selected [1]. On the network other demand customers are connected and will continue to be so with the ESS. Hence, they will require the same type of availability and service as before the connection of the ESS. The storage device is installed at Hemsby at a normally open point between two primary substations, near the remote ends of $11 \mathrm{kV}$ feeders from the substations. Only one feeder is connected to the ESS at any single moment, but it is easy to switch between feeders, allowing for different operational scenarios. Physical network information such as line and transformer data is provided by the Distribution Network Operator, DNO, as well as half-hourly operational data comprising feeder current and DG output. Fig. 2 shows a single-line diagram of the network with the ESS located at the center of the upper part.

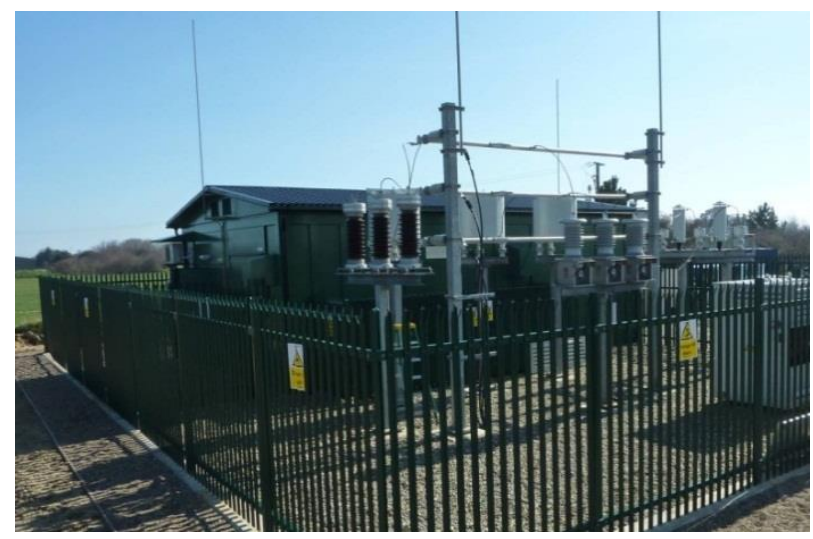

Fig. 1. Dynamic energy storage 


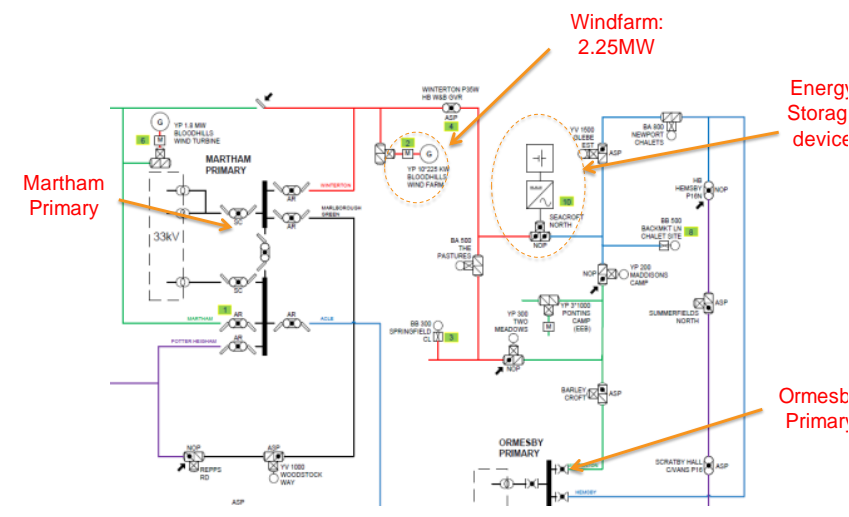

Fig. 2. Network SLD, showing location of primary substations, wind generators and dynamic energy storage

A mixture of residential areas, rural areas and seasonally occupied accommodation are supplied by the feeders in this region [1]. The typical load on the feeders is $1.15 \mathrm{MW}$ and $1.30 \mathrm{MW}$ with peaks of $2.3 \mathrm{MW}$ and $4.3 \mathrm{MW}$ respectively. The wind farm with $2.25 \mathrm{MW}$ installed capacity is attached midway along the first of these feeders. This installation has fixed speed induction generators, so there is significant reactive power demand while generating.

Daily load profiles show that the two feeders have quite different characteristics [1]. On the first, the most significant demand occurs during the night, due to a high number of homes heated by night storage heaters. Summer loading is lower than during winter. The second feeder has much less storage heating, and in this case summer loading is higher than during winter. These dissimilar characteristics mean that events requiring ESS support are likely to occur at different times, maximizing the utilization of the ESS.

A range of modeling and simulation work has been carried out by Durham University to evaluate the most effective way to operate the ESS on a distribution network.

Funding for the monitoring and evaluation phase of the work has been secured by UK Power Networks from the GB Regulator Ofgem as a Tier One Low Carbon Networks Fund, LCNF, project together with matching funding from ABB. This phase of the project will help confirm the modeled benefits by running a series of network tests and measuring key points on the network and comparing with the predicted model values. Experience of operating the Energy Storage System will also provide valuable experience for UK Power Networks and other Utility companies considering placing energy storage onto their distribution and transmission networks.

\section{DYNAPEAQ}

The Hemsby ESS is realized through DynaPeaQ, which is a dynamic energy storage system based on Li-ion battery storage combined with SVC Light, ABB's STATCOM concept, to be connected to the grid at transmission as well as sub-transmission and distribution levels. State of the art IGBTs, Insulated Gate Bipolar Transistors. are utilized as switching devices. ABB is aiming for industry, distribution and transmission level energy storage applications. Especially the focus is on applications where the combined use of continuous reactive power control and short time active power support is needed.

DynaPeaQ enables dynamic control of active as well as reactive power in a power system, independently of each other. By control of reactive power, grid voltage and stability are controlled with high dynamic response. By control of active power, new services based on dynamic energy storage are introduced, such as:

- Black start support of grids

- First minute emergency power supply until emergency generation is on line

- Provide power to support frequency regulation (primary and secondary frequency support)

- Capacity firming for wind/solar generation to generate higher forecasted levels of renewable production (having a stochastic behavior)

- Ramping support, to avoid power system disturbance, when renewable generation is quickly dispatched

- Storing power as alternatives to T\&D investments for peak load support

- Reducing peak power to gain on tariffs, for instance for fast charging EV, Electric Vehicles, and industrial loads

With these benefits, DynaPeaQ can be expected to come out as a qualified enabler of Smart Grid.

DynaPeaQ's ability to store energy is highly scalable. At present, rated power and storing capacity are typically in the range $20 \mathrm{MW}$ during tens of minutes, but up to $50 \mathrm{MW}$ during 60 minutes and beyond is possible. In some perspective, as battery prices are anticipated to go down, applications requiring larger battery storage will become viable, such as multi-hour storing of renewable power during low demand for release into the grid during higher demand.

\section{MAIN CIRCUIT DESIGN}

DynaPeaQ is connected to the grid at the Point of Common Coupling, PCC, through a phase reactor and a power transformer, see Fig 3 for details. Having both capacitors and batteries, it can control both reactive power, Q, as an ordinary SVC Light, as well as active power, P, thanks to the batteries.

SVC Light is based on Voltage Source Converters, VSC, connected in shunt to the grid at transmission as well as subtransmission and distribution levels [4]. The grid voltage and the VSC current set the apparent power of the VSC, whereas the energy storage requirements decide the battery size. As a consequence, the peak active power of the battery may be smaller than the apparent power of the VSC: for instance, 10 MW battery power for an SVC Light of \pm 30 Mvar. To support the grid during contingencies, as well as for ancillary services, it is enough to have the necessary amount of power available during a relatively short time. An energy storage system can then provide the necessary surplus of active power and then be recharged from the grid during normal 
conditions.

The VSC is built up of IGBT and diode semiconductors, four IGBT valves and two diode valves in each phase leg. To handle the required valve voltage, the semiconductors are connected in series. Water cooling is utilized for the VSC, giving a compact converter design and high current handling capability.

Each IGBT and diode component is built up in a modular housing comprising a number of sub-modules, each containing a number of semiconductor chips (ABB $\mathrm{StakPak}^{\mathrm{TM}}$ ). The collector and the emitter of the IGBT are the top and bottom respectively, meaning that the current flows vertically in the IGBT stack. An IGBT consists of up to six sub-modules, where the number of sub-modules determines the current capability of the component.

The short-circuit failure mode of an IGBT is one of the most critical parameters. The StakPak IGBT will fail as shortcircuit, which enables continued operation without tripping the converter, with the only outcome that the other components in the valve will be subject to somewhat higher voltage.

The DynaPeaQ has a dynamic reactive power range from 600 kvar inductive to 725 kvar capacitive. The battery storage connected to the DC side of the VSC can deliver $200 \mathrm{~kW}$ for one hour, or $600 \mathrm{~kW}$ for a short period. The design is based on IEC standards and on the vast experience gathered from other plants utilizing SVC Light.

The Li-ion battery technology selected for DynaPeaQ benefits from a number of features:

- High energy density

- Very short response time

- High power capability both in charge and discharge

- Excellent cycling capability

- Strongly evolving technology

- High round trip efficiency

- High charge retention

- Maintenance free design

\section{A. High-voltage interface}

The 1 MVA step-down transformer together with a $2.2 \mathrm{kV}$ busbar, voltage monitoring, AC coupling reactor and harmonic filter are placed outdoor in a compact arrangement in a small yard.

\section{ESS TESTING}

It should again be noted that the ESS has been installed as a demonstration project on a region of $11 \mathrm{kV}$ network operated by a UK DNO, and as such, the network already operates within technical and statutory limits at all times. Interventions that are made by the ESS are in response to more tightly constrained control objectives that have been devised in order to test the ability of the ESS and the control algorithm to operate in a way that is acceptable to the control engineers responsible for the network.

The four-quadrant VSC allows independent setting of real and reactive power either into or out of the ESS. This facility can be used to support the $11 \mathrm{kV}$ distribution feeder in a number of ways that can be broadly divided into two categories, voltage control and power flow management. Voltage control can be carried out in response to measurements in a range of locations on the feeder, either at the PCC of the ESS, the remote end of the feeder or a mid-point in the region of the location of the wind-farm. Voltage can be influenced by supplying or receiving real or reactive power or a combination of both. Power flow management can take place in response to several measurements from the network including feeder power flows (real or reactive), wind-farm real power output or reactive power demand, or mid feeder power flow.

The energy storage system has a control system that manages the operation of the power electronic converter, protection systems and safety features. A separate system is hosted on a ruggedized PC located at the feeding primary substation that will issue real and reactive power set points to the ESS control system. This control system gathers measurements locally at the primary substation and from remote points on the network to supply the algorithm with information on the current network conditions. The algorithm is supplied with voltages at each end of and midway along the feeder, power flow on each feeder out of the substation, onload tap changer position, wind-farm power output and breaker status. The algorithm is configured to tackle one or more of the network control objectives and follows a hierarchical rule-based system to determine the energy storage system real and reactive power set-points. As an example, a rule can be defined to supply power from the ESS when the power onto the feeder $\mathrm{P}_{\text {feed }}$ exceeds a threshold $\mathrm{T}_{\text {feed }}$. This rule is expressed in a case statement as:

$$
\mathrm{P}_{\mathrm{ESS}}=\left\{\begin{array}{cc}
\mathrm{P}_{\text {feed }}-\mathrm{T}_{\text {feed }} & \text { if } \mathrm{P}_{\text {feed }}>\mathrm{P}_{\text {feed }} \\
0 & \text { otherwise. }
\end{array}\right.
$$

This way of configuring the control algorithm requires prior knowledge of the network operating conditions, commensurate with the level of understanding required before deciding to deploy an ESS, particularly in the case of a trial deployment. The actions of the control algorithm are transparent to the network operator and all decisions made can be logged, and then examined and evaluated retrospectively.

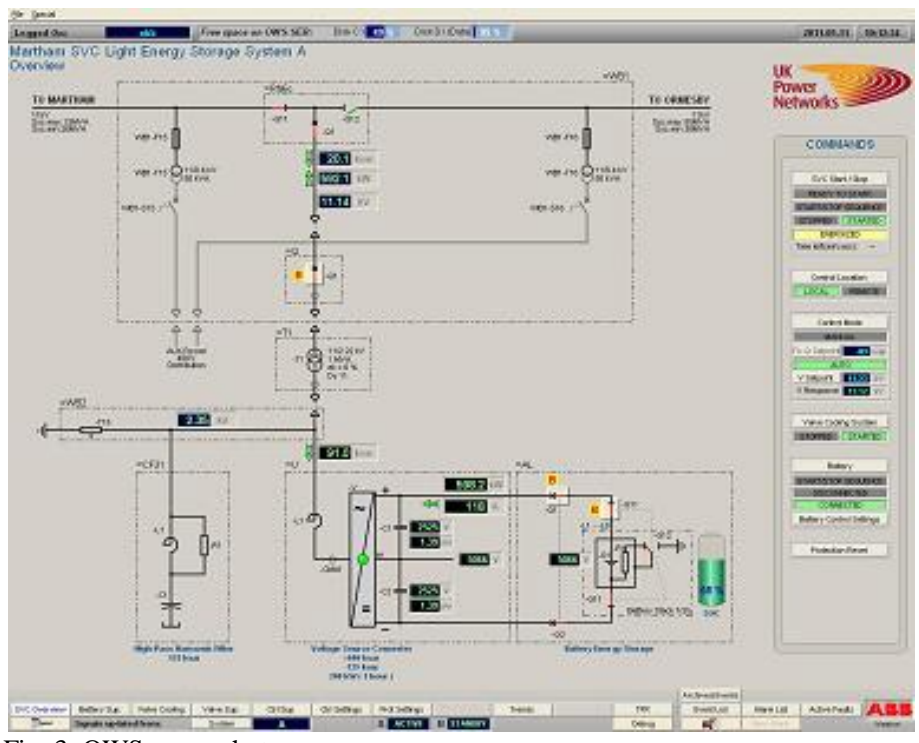

Fig. 3. OWS screenshot 


\section{ESS FIELD OPERATION}

\section{A. Commissioning results}

The commissioning comprised basically two parts; one related to the battery interface constituted by a standard SVC Light and one part related to the energy storage.

One of the tests performed during the commissioning related to the energy storage was made to verify the active power capacity. Both the one-hour $200 \mathrm{~kW}$ as well as the short-time $600 \mathrm{~kW}$ capacity were successfully finalized. During the test, the fault level was less than 100 MVA.

Figure 4 shows results from the initial part of the $600 \mathrm{~kW}$ test. At the discharge start, the batteries are fully charged and the SOC is at $100 \%$, see curve a) and d) of Fig. 4. Full power order is issued at the time equal to $25 \mathrm{~s}$ and the power is then quickly ramped from zero to full power as illustrated by curve c). The instant voltage drop in curve a) just after the discharge has been initiated is due to the resistive voltage drop in the batteries caused by the current. Throughout the discharge the SOC is continuously decreased, which is also seen in the decreasing voltage in curve a). To keep the power in curve c) constant and according to the order, the battery current in curve b) is increased (note that the current is defined as negative for discharge).

\section{B. STATCOM automatic voltage control}

The MACH2 controller in the ESS can be programmed to follow a pre-defined control curve that brings the voltage at the PCC toward a target set-point. To prevent excessive operation a dead-band around the target voltage is imposed. If voltage deviates beyond the dead-band, reactive power is delivered or absorbed with a magnitude proportional to the extent of the voltage deviation.

Results measured from the network in Fig. 5 show the action of the STATCOM automatic voltage control. In order to make a comparison with the effect that would have been seen without the ESS in operation, a load flow has been carried out to simulate the voltage at the PCC, both with and without the ESS. For this early test, limited data acquisition was available on the network so the voltage at the PCC is simulated from measurements at the primary substation. This situation limits the clarity of the effect of the STATCOM but the raising of low voltages and trimming of high voltages can be seen.

The parameters for the STATCOM operation were changed in the summer of 2012, to make the system compensate for voltage within stricter limits [5]. The deadband settings were tightened from $10.96 \mathrm{kV} \pm 0.11 \mathrm{kV}$ to $\pm 0.08 \mathrm{kV}$, whereby lower levels of voltage variation would prompt a response from the ESS. The impact can be seen in Fig. 6 and Fig. 7, illustrating an increased number of reactive power exchanges after the settings were changed, and the voltage being kept within stricter limits [5].

\section{Real power exchange}

Real-power operations have been carried out on the ESS in the initial exploration of the effect of the device on the network. Results in Fig. 8. show two export/import cycles at $100 \mathrm{~kW}$ and $75 \mathrm{~kW}$ respectively. At the end of the charge cycle, the effect of reaching the maximum battery state-ofcharge can be seen, as the control system tapers the charge power down to zero.

The impact on the feeder power measurements can be clearly seen in the comparison of the recorded feeder power and what would have occurred had the ESS not been in operation. There is considerable variability in the underlying demand curve due to both varying demand and generation from the wind-farm on this feeder.

Analysis of the STATCOM operation and first real power exchange schemes have demonstrated, as expected, that the ESS is able to [5]:

- $\quad$ Reduce demand by exporting real power;

- Reduce voltage fluctuations by exporting or importing reactive power to increase or lower the voltage, respectively

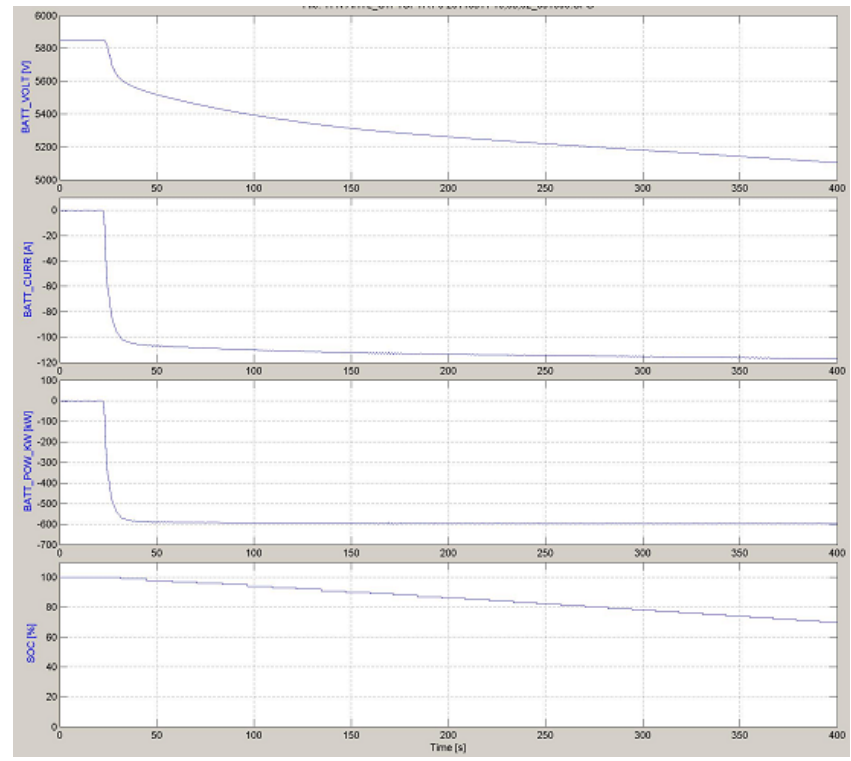

Fig. 4. Field test of $600 \mathrm{~kW}$ capacity, first $400 \mathrm{~s}$.

a) Battery voltage

b) Battery current

c) Battery power

d) Battery SOC

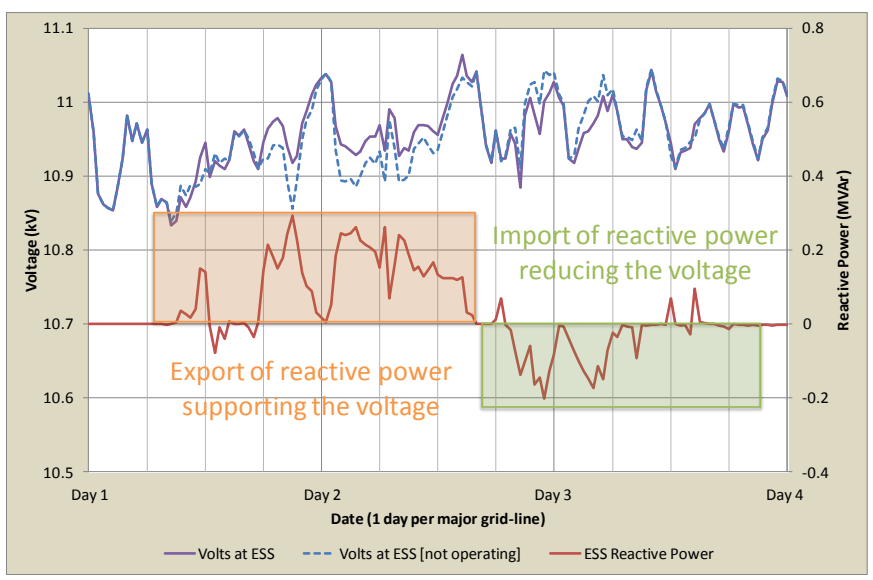

Fig. 5. Reactive power exchanges with network to support voltage stability 


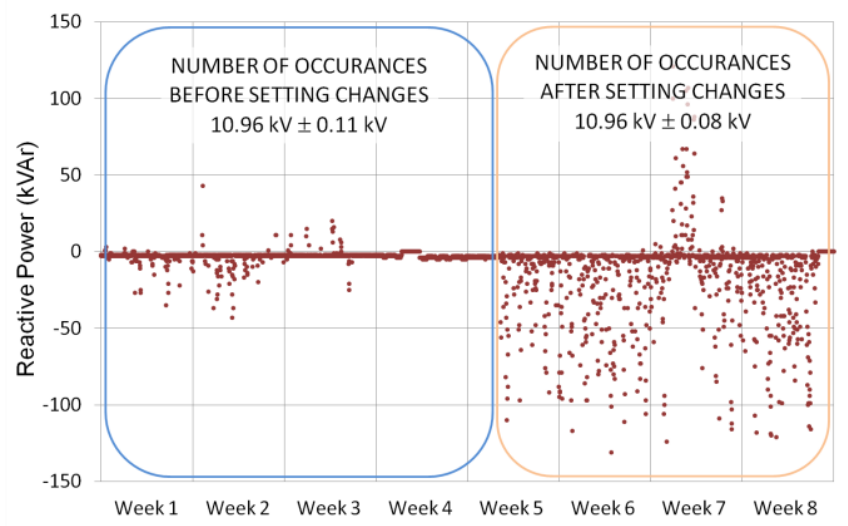

Fig. 6. Impact of changes to STATCOM parameters (occurrences of kVAr exchange)

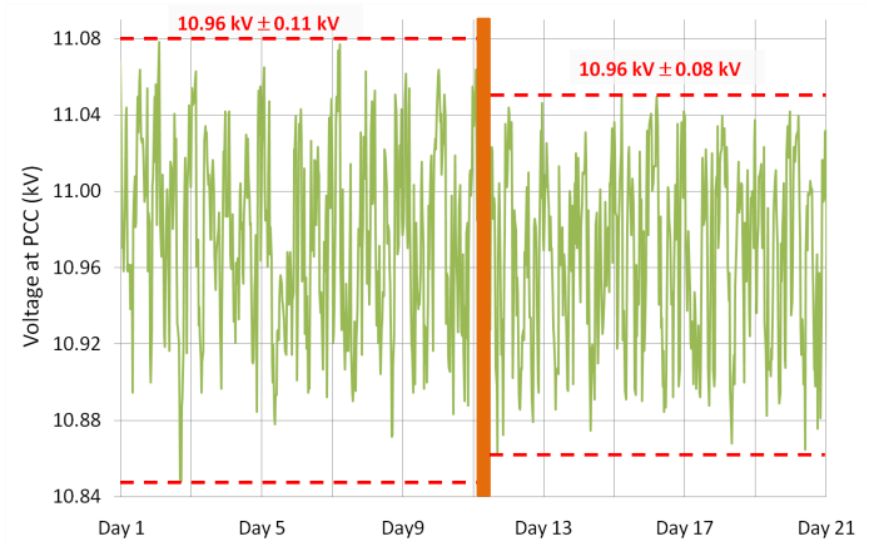

Fig. 7 Impact of changes to STATCOM parameters (voltage kept within stricter limits)

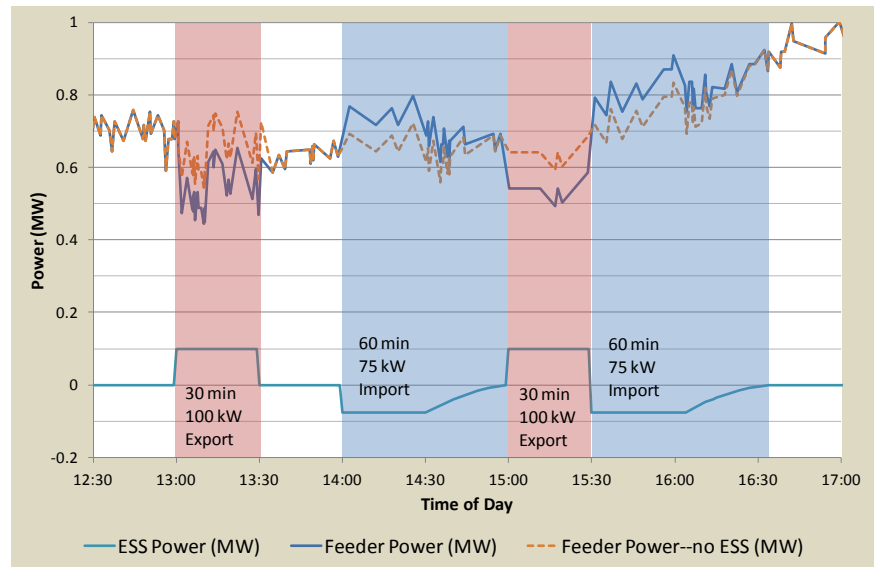

Fig. 8. Real power exchange with the network

It can be concluded that the impact of being able to reduce fluctuations and manage demand is that it provides the possibility to accommodate additional demand or generation on the existing feeders, within the thermal limits of the plant and circuit, without breaching voltage limits or needing to curtail generation.

\section{CONCLUSIONS}

UK Power Networks has installed a dynamic energy storage system at Hemsby in Norfolk in England in collaboration with $\mathrm{ABB}$, and Durham University. The purpose is to test the functionality of the energy storage concept in conjunction with a small wind farm and try out various applications such as levelling out short time power fluctuations from the wind farm and storing energy during low demand, to be released into the grid during high demand.

The installation phase of the project was financially supported through GB regulator Ofgem's Innovation Funding Incentive scheme. Funding for the monitoring and evaluation phase of the work has been secured from the GB regulator Ofgem as a Tier One Low Carbon Networks Fund, LCNF, project.

The system is based on SVC Light, ABB's STATCOM concept, combined with a Li-ion battery storage and is located in an $11 \mathrm{kV}$ grid with considerable penetration of wind power.

A range of modelling and simulation work has been carried out by Durham University to evaluate the most effective way to operate the ESS on a distribution network.

UK Power Networks has started to implement a number of power exchange schemes, and will start testing algorithmic control of the ESS early in 2013.

\section{REFERENCES}

[1] N. Wade, P. Taylor, P. Lang, J. Svensson, "Energy storage for power flow management and voltage control on an $11 \mathrm{kV}$ UK distribution network," CIRED paper 0824, Prague, Czech Republic, June 2009.

[2] P. Lang, N. Wade, P. Taylor, P. Jones, T. Larsson, "Early findings of an energy storage practical demonstration," CIRED paper 0413, Frankfurt, Germany, June 2011.

[3] P. Lang, M. Michel, N. Wade, R. Grünbaum, T. Larsson, "Dynamic Energy Storage - A UK first, IET ACDC conference, Birmingham Dec. 5-6 2012

[4] J. Svensson, W. Hermansson, "Dynamic energy storage using SVC Light," Cigré paper B4-204, Paris, 2008.

[5] "Early learning from an electrical storage installation on an $11 \mathrm{kV}$ distribution network", Report, UK Power Networks, October 2012 